\title{
Investigation on the Antibacterial Activity and Phytochemical Screening of the Fruit Seed Extracts of Agro Waste
}

Abbas Asaad ${ }^{1}$, Shakinaz Desa ${ }^{1}$, Syarul Nataqain Binti Baharum ${ }^{2}$, Alsailawi. H. A ${ }^{1}$, Alhussein Arkan majhool ${ }^{3}$, Mustafa Mudhafar ${ }^{3}$, M. M. Abdulrasool ${ }^{3}$ and Latifa Nasser ${ }^{4}$

1. Department of Biology, Faculty of Science and Mathematics, Sultan Idris Education University, Tanjong Malim 35900, Perak

2. Institute of Systems Biology, Universiti Kebangsaan Malaysia (UKM), Bangi 43600, Selangor, Malaysia

3. Department of Chemistry, Faculty of Science and Mathematics, Sultan Idris Education University, Tanjong Malim 35900, Perak

Darul Ridzuan, Malaysia

4. Dr. Babasaheb Ambedkar Marathwada University, University Campus, Maharashtra 431004, India

\begin{abstract}
The primary objective of this study is to evaluate the seed extracts from agro waste to examine the effectiveness of antimicrobial. Therefore, by using the disc diffusion assay, the antibacterial activity was evaluated along with two medically important bacterial pathogens such as methicillin resistant Staphylococcus aureus (S. aureus) (MRSA) and Escherichia coli (E. coli) in the seed extracts of Cucurbita sp., Carica papaya L., Nephelium lappaceum, Mangifera indica, Durio zibethius and Artocarpus heterphyllus Lam seeds. Seed extracts of agro waste were analyzed for the phytochemical constituents. Analysis of the qualitative phytochemical indicated the importance of phytochemical compounds for instance glycosides, saponins, flavanoids, tannins and alkaloids. Variations had been seen in the inhibition zone depending on the species and different seed extracts concentrations used for bacteria, the highest inhibition zone observed for M. indica and C. papaya $\mathrm{L}$. The obtained data of this study presented greater insights which allow the use of seed extracts that were obtained from the agro-waster, to be used as raw materials for food, chemical, and pharmaceutical industries.
\end{abstract}

Key words: Agro waste, seed extracts, Phytochemical Screening, Antimicrobial Activity

\section{Introduction}

Agrowaste is considered as the valuable assert in the world. They are broadly accessible and are considered as an important source due to their properties like renewable and virtually free $[1,2]$. Technically, it exists worldwide concern regarding the use of agricultural waste. Such waste is the part of product from various agricultural processes which are known as agricultural residues instead of agrowaste. Additionally, it contains materials of economic value [3]. Nevertheless, it is possible to take advantages of the agrowaste by converting it into human food and manufacturing it to achieve horizontal agriculture,

Corresponding author: Assistant professor Dr. Shakinaz Desa, protect the environment from pollution, improve agricultural products, and provide employment opportunities in the agricultural sector. Thus, improvement of the economic situation, environment as well as rise in the health and social level, especially in rural areas, can be witnessed [4]. Furthermore, the highest amount of agrowaste was obtained during harvest, collection of crops, and preparation for marketing. These wastes are rich in recyclable materials which contain organic matter and minerals $[2$, 5]. Based on extensive literature review, the viabilities and limitations of recovering waste from food processing were presented. From the transformation, the main uses and applications of functional ingredients were presented to the pharmaceutical and nutraceutical fields. 
From the context of Malaysia, about 1.2 million tons of wastes that are produced from agricultural activities are disposed into the landfills yearly [6]. Approximately $15 \%$ of the entire waste produced in various Asian countries is agrowaste. It has been reported that rural waste production in Malaysia was roughly 0.122 (kg/top/day) in 2009 and by 2025 it is anticipated to achieve 0.210 (kg/top/day). Additionally, such waste has most of its use limited to the animal food industry or is disposed in the environment, causing serious environmental damages [3, 4, 6, 7].

However, these wastes have high content of sugars, vitamins, and mineral nutrients such as fibres, oil, and other compounds with various functional properties. This indicated that these wastes are highly potential. Thus, investigations are being conducted and continuously emerging onto special oils that exist in diet and their role in the matter of food quality as well as the impact onto the consumers' health.

Additionally, the incorporation of waste into the production of high quality special oils and into the food, pharmaceutical, chemical or cosmetic industries can improve the product availability, in order to cover the emerging needs for new oil sources. For this reason, studies search for raw materials that provide oils of lipid profile that is similar to those from traditionally consumed oils, and which are also alternative sources of phytosterols and phenolic compounds [1, 8-10].

Moreover, the existence of bioactive compounds such as flavonoids, alkaloids, carbohydrates, cardiac glycosides, tannins, steroids, terpenoids and coumarins, allows the oils taken from the fruit seeds to become the alternative sources for oils with a function to reduce the risk of getting a disease if being taken too often.

In this study, the main objective is to evaluate the seed extracts from Cucurbita sp. seeds, C. papaya $\mathrm{L}$. seeds, $N$. lappaceum seeds, $M$. indica seeds kernel, $D$. zibethius seeds, and A. heterphyllus Lam seeds, as to the level of bioactive compounds (alkaloids, saponins, carbohydrates, cardiac glycosides, tannins, steroids, terpenoids, flavonoids and coumarins), antimicrobial capacity of such seed extracts.

\section{Materials and Methods}

\subsection{Plant Material}

The seeds of D. zibethius, A. heterphyllus Lam, Cucurbita sp., C. papaya L., N. lappaceum and M. indica were collected from the Agrowaste in district of Muallim, Perak, Malaysia.

\subsection{Oil Extraction}

The Soxhlet extraction (SE) method was used to extract from the seeds. The dehydrated seeds were crushed using the electric grinder. Later, the powder was stored in polyethylene bags and conserved at the room temperature until the seed extracts process. SE was performed with a Soxhlet apparatus, the seed extracts of powdered sample from the plant seeds using $\mathrm{n}$-hexane for around 8 hours at $50-60{ }^{\circ} \mathrm{C}$. After the completion of extraction, the hexane mixture was passed through a layer of anhydrous magnesium sulphate placed over a filter paper in a funnel, using a rotary evaporator (Model R-200, made in Switzerland), n-hexane was detached at the temperature of $40{ }^{\circ} \mathrm{C}$ under a reduced pressure. Then, the flask was subsequently placed in a desiccator chamber for 1 hour to remove the remaining $\mathrm{n}$-hexane and later, was stored at $20^{\circ} \mathrm{C}$ for further analysis.

\subsection{Phytochemical Screening}

Phytochemical screening was carried out for plant seed extracts from Cucurbita sp., C. papaya L., N. lappaceum, $M$. indica, $D$. zibethius and $A$. heterphyllus Lam as per the standard methods [11, 12].

(1) Alkaloids test: each of the six seed extracts was dissolved individually in a dilute HCL acid and later being filtered. Then, the filtrates were treated separately with Mayer's, Wagner's and Dragendroff's Reagent to look for the presence of alkaloids.

- Mayer's test: to a few $\mathrm{mL}$ of filtrate, a drop or two of Mayer's reagents are added by the side of the 
test tube. A white or creamy precipitate indicates the test as positive.

- Wagner's test: few drops of Wagner's reagents are added to a few $\mathrm{mL}$ of the filtrate by the side of the test tube. A reddish-brown precipitate confirms that the test is positive.

- Dragendorff's test: 1 or $2 \mathrm{~mL}$ of Dragendorff's reagents are added to a few $\mathrm{mL}$ of filtrate. A noticeable yellow precipitate exhibits that the test is positive.

(2) Saponins test: $0.5 \mathrm{~mL}$ of seed extracts with 2.5 $\mathrm{mL}$ of distilled water are combined and shaken vigorously. Later, let it stand for couple of minutes. Based on the observation, there is an advancement of foam on the surface of the mixture to show the presence of saponins.

(3) Carbohydrates test: all seed extracts were dissolved exclusively in $5 \mathrm{~mL}$ of distilled water and later being filtered. Subsequently, the filtrates were treated with Molish's reagent to test for the presence of sugars. Based on the observation, violet ring formation means positive test.

(4) Cardiac glycosides test: to $0.5 \mathrm{~mL}$ of seed extracts, add $1 \mathrm{~mL}$ of Iron (III) chloride reagent and few drops of concentrated $\mathrm{H}_{2} \mathrm{SO}_{4}$, to test for the presence of cardiac glycosides. The presence of greenish-blue colour indicates the existence of cardiac glycosides based on the positive test.

(5) Tannins test: into $0.5 \mathrm{~mL}$ of seed extracts, include $2 \mathrm{~mL}$ portion of the $0.1 \%$ ferric chloride to test for the presence of tannins. Positive test shows brownish green or blue black colorations.

(6) Steroids test: add $5 \mathrm{~mL}$ of chloroform to $0.5 \mathrm{~mL}$ of seed extracts and gradually put $5 \mathrm{~mL}$ of sulphuric acid by the sides of the test tube to test the availability of steroids. If the upper layer turns red and the sulphuric acid layer showed the yellow color with green fluorescent, it indicates that it is a positive test.

(7) Terpenoids test: to $0.5 \mathrm{~mL}$ of seed extracts, add $1 \mathrm{~mL}$ of chloroform and carefully include condensed sulphuric acid precisely couple of drops, for testing the presence of terpenoids. Reddish brown coloration is showed by positive test.

(8) Flavonoids test: add $2 \mathrm{~mL}$ of $1 \%$ aluminums solution to $0.5 \mathrm{~mL}$ of seed extracts. Positive indication indicates the presence of flavonoid showed by the yellow color.

(9) Coumarins test: to $0.5 \mathrm{~mL}$ of seed extracts, add $3 \mathrm{~mL} \mathrm{NaOH}(10 \%)$, to test for the presence of coumarins test. Positive test shows yellow coloration.

\subsection{Antimicrobial Activity Test}

\subsubsection{Agar Preparation}

Eight (8) $\mathrm{g}$ of LB broth known as Lennox and $20 \mathrm{~g}$ of agar powder were dissolved in $1000 \mathrm{~mL}$ of distilled water. Later, the mixture was sterilized by an autoclave for 20 minutes at the temperature of $121^{\circ} \mathrm{C}$. Then, it was left to cool at $55{ }^{\circ} \mathrm{C}$ with $25 \mathrm{~mL}$ of cooled media added to the plate and left for some time to solidify. Finally, in a dark room, it was stored at 4 ${ }^{\circ} \mathrm{C}$ for further observation.

\subsubsection{Antimicrobial Test}

This is the qualitative method of testing anti-bacterial efficacy. However, it illustrated that for the disc diffusion assay the seed extracts were dissolved in hexane (concentrations extending from 15 to $35 \mathrm{mg} / \mathrm{mL}$ ) [13]. After that, $20 \mu \mathrm{L}$ of the extract solution was pipetted onto a $6 \mathrm{~mm}$ diameter sterile disc which is made by Whatman filter paper. The disc containing the extract was allowed to dry in the laminar air flow for few minutes. The disc was then placed gently on the Mueller Hinton agar plates that had been inoculated with the bacteria suspension using a sterile forceps. In this study, there were two controls used which were solvent containing disc as the negative control and commercially antibiotic containing disc ampicillin as the positive control for Methicillin-resistant $S$. aureus and E. coli respectively. Within 30 minutes of discs application, the plates were incubated aerobically in an inverted position at $37{ }^{\circ} \mathrm{C}$ for 24 hours. Inhibition zones diameter around the discs was measured and recorded to the nearest 
millimeter $(\mathrm{mm})$ at the end of the incubation time.

\subsubsection{Bacterial Strains}

The bacteria species that used in the antibacterial activity are shown in Table 1.

\section{Results and Discussion}

\subsection{Phytochemical Screening}

Phytochemical screening was conducted out for plant seed extracts from Cucurbita sp., C. papaya L., $N$. lappaceum, M. indica, $D$. zibethius and $A$. heterphyllus Lam. Nine phytochemical screening tests have been carried out. This included alkaloids, saponins, carbohydrates, cardiac glycosides, tannins, steroids, terpenoids, flavonoids, and coumarins tests. Any change of colours or the precipitate formation is used as indication of positive response to these tests and results which are tabulated in Table 2. Based on the phytochemical analysis, the outcome had revealed that important chemicals like alkaloids, carbohydrates, flavonoids, and saponins were found to be present in all tested seed extracts, while terpenoids and cardiac glycosides were found to be present in most of seed extracts. Although plant alkaloids are said to be active against bacterial, yet they are also widely utilized in the treatment of skin disorders such as eczema, seborrheic dermatitis, and neurodermatitis [14]. Additionally, these plant steroids are commonly used in cosmetic, soap, and pharmaceutical industries to create creams, ointments, and soaps and served to be as treatment against inflammatory diseases [15]. Besides that, saponins are mostly soap-forming compounds that also have antimicrobial property. Their action of mechanism can lead to the leakage of the protein or certain enzyme from the bacteria cells. In addition, saponins can also be used in anticancer, antifungal, antioxidant, and weight loss treatment [16, 17]. Meanwhile, Jayashree [17] mentioned that terpenoids compounds have been highlighted to possess

Table 1 The bacteria strains used in the antibacterial activity.

\begin{tabular}{ll}
\hline Bacteria species & ATCC number \\
\hline Gram positive & 6,538 \\
Methicillin-resistant Staphylococcus aureus (MRSA) & \\
Gram negative & 35,218 \\
Escherichia coli &
\end{tabular}

ATCC: American Type Culture Collection.

Table 2 Phytochemical screening of seed extracts from selected plants.

\begin{tabular}{|c|c|c|c|c|c|c|c|}
\hline & & & Seed & & & & \\
\hline & Phytochemical test & A & B & $\mathrm{C}$ & $\mathrm{D}$ & $\mathrm{E}$ & $\mathrm{F}$ \\
\hline \multirow[t]{4}{*}{1} & Alkaloids test & & & & & & \\
\hline & Mayer's & + & + & + & + & + & + \\
\hline & Wagner's & + & + & + & + & + & + \\
\hline & Dragendroff's & + & + & + & + & + & + \\
\hline 2 & Saponins test & + & + & + & + & + & + \\
\hline 3 & Carbohydrates & + & + & + & + & + & + \\
\hline 4 & Cardiac glycosides & - & + & - & + & + & - \\
\hline 5 & Tannins test & - & - & - & + & + & + \\
\hline 6 & Steroids test & + & - & + & + & + & + \\
\hline 7 & Terpenoids test & + & + & + & - & + & - \\
\hline 8 & Flavonoids test & + & + & + & + & + & + \\
\hline 9 & Coumarins test & - & - & - & + & - & - \\
\hline
\end{tabular}

+: test positive; -: test negative.

A: A. heterophyllus; B: Cucurbita sp., C: C. papaya L., D: N. lappaceum; E: M. indica, F: D. zibethinus. 
antibacterial, antidiarrhoeal, antiviral, and antineoplastic effect. In order to allow the heart to function more efficiently, cardiac glycosides are commonly applied to treat heart diseases by strengthening the heart tissues [18]. Additionally, they can prevent the sodium ions, $\mathrm{Na}^{+}$pump and decrease the concentration of $\mathrm{Na}^{+}$ions in the myocytes. Consequently, the amount of calcium ions, $\mathrm{Ca}^{2+}$ will increase and be available for the heart muscle. According to Ref. [19], it then can lead to an increment to the cardiac output and decrement in the distension of heart.

\subsection{Antimicrobial Screening}

Differences in the zone of inhibition of six species with different extracts are shown in Figs. 1-3 which show the zone of inhibition exhibited by the positive and negative control against MRSA and E. coli that used ampicillin as positive control. The activities of different seed extracts against various bacteria are shown in Table 3. The zone of inhibition increased with the seed extract concentration. All extracts exhibited activity against E. coli and MRSA. However Cucurbita sp. extract did not show any activities in different concentrations.

$M$. indica and C. papaya L. showed the highest zone of inhibition of $13 \mathrm{~mm}$ at $35 \mathrm{mg} / \mathrm{mL}$ in MRSA. However, D. zibethinus had the highest zone of inhibition of $12 \mathrm{~mm}$ at $35 \mathrm{mg} / \mathrm{mL}$ in E. coli. The antibacterial activities of these oil extracts against $E$. coli and MRSA might be due to the presence of flavonoids, polyphenols, saponins, and tannins. Oil extracts of sulfur-rich plants might have potent antimicrobial activities [20].

Cucurbita sp. extract did not show any activity toward the E. coli bacteria in different concentrations. This result might be due to other phytochemical compounds present in the extract that might have interfered with its antibacterial activity. These other phytoconstituents might exert antagonistic effect on the bioactive compounds that perform antibacterial activity [21].

Specific compounds with antibacterial activity have not been determined in this study. However, the phytochemical compounds of plant seed extracts had been preliminarily screened. Phytochemical screening revealed that alkaloids are present in all tested seeds oil,

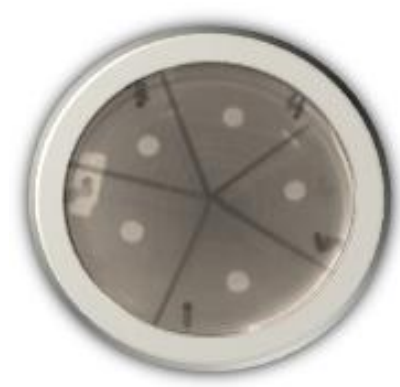

Cucurbita sp

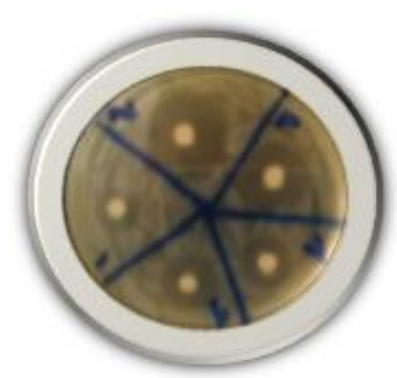

C. Papaya $L$

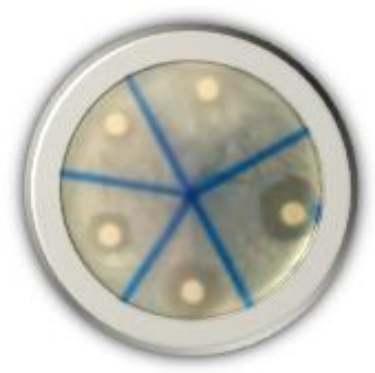

M. indica

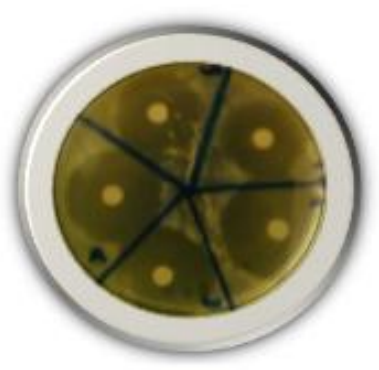

N. lappaceum

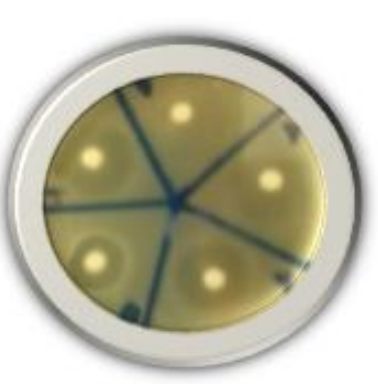

A. heterophyllus

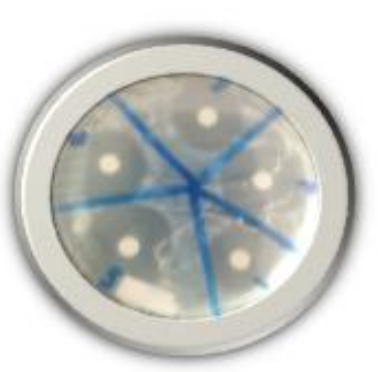

D. zibethinus

Fig. 1 Inhibiting bacteria (E. coli) through seed extracts. 


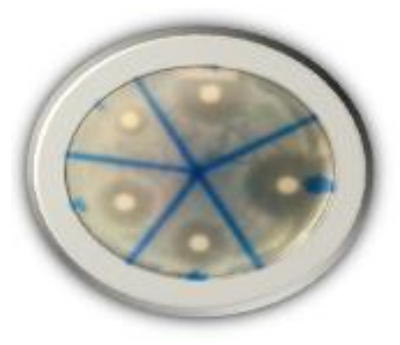

Cucurbita $s p$

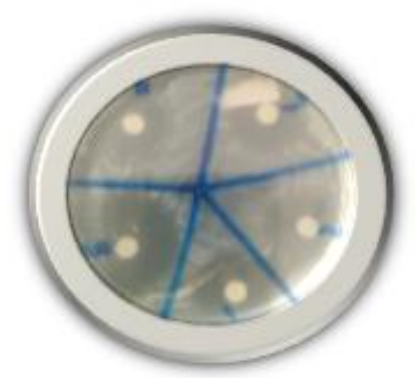

C. Papaya $L$

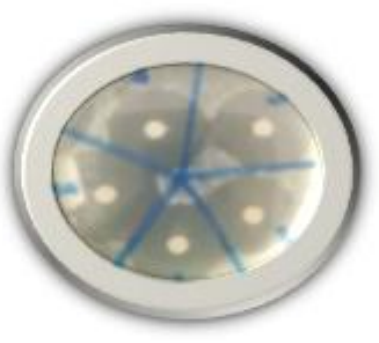

M. indica

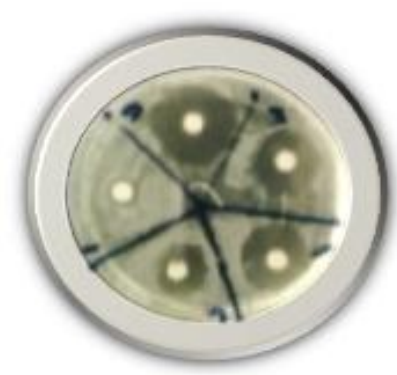

N. lappaceum

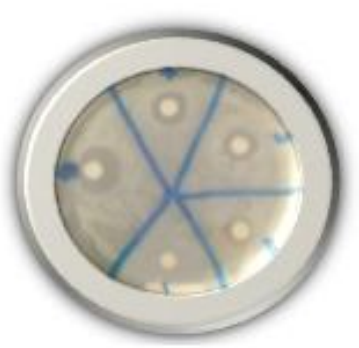

A. heterophyllus

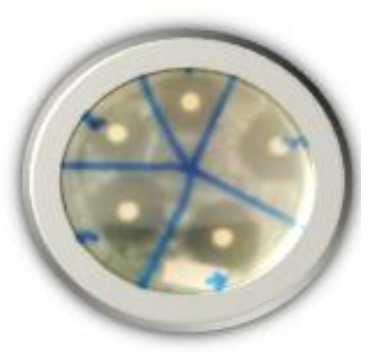

D. zibethinus

Fig. 2 Inhibiting bacteria (MRSA) through seed extracts.

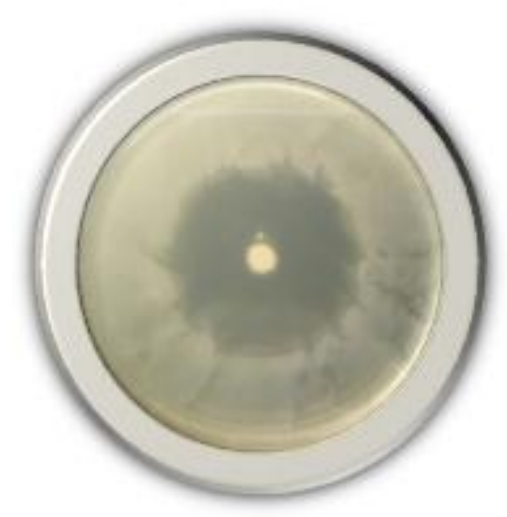

MRSA

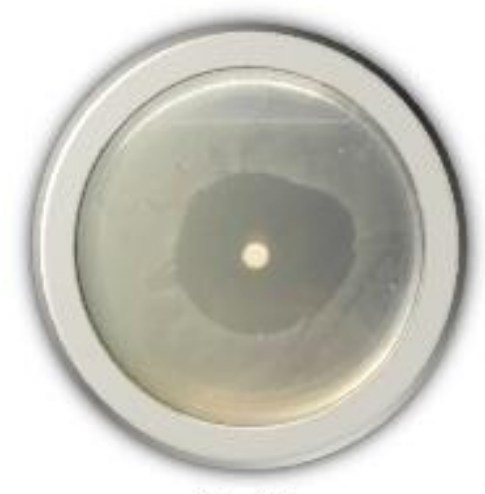

E. coli

Fig. 3 Zone of inhibition by positive control against MRSA and E. coli.

and terpenoids are present in most of extracts seed.

Thus, both compounds are potential antibacterial agents. The antibacterial activity of these extracts may be due to the individual or combination effects of terpenoids groups. The proposed terpenoid lactones involved in antibacterial activity are andrographolide, 1,4-deoxyandrographolide, and neoandrographolide [14, 22].

All seed extracts of plants are less susceptible to gram-negative bacteria than to gram-positive bacteria. This phenomenon occurs because gram-negative bacteria have a cell wall structure that contains an extra layer of outer membrane compared with that of gram-positive bacteria that only have an inner cell membrane. This outer membrane has a structure similar to that of lipopolysaccharide components and can prevent drugs and antibiotics from entering the cell [23]. By contrast, the outer peptidoglycan layer of gram-positive bacteria is permeable to the antimicrobial chemical substances. Thus, gram-negative bacteria are less susceptible to antibacterial inhibition caused by agents in the 
seed extracts compared with gram-positive bacteria $[20,24]$. These results serve as reference on the use of oils extracted from agro-waste for the management of microbial infections and as raw material for food, chemical, and pharmaceutical industries.

Table 3 Antibacterial activity of seed extracts at different concentrations.

\begin{tabular}{|c|c|c|c|}
\hline \multirow[t]{2}{*}{ Botanical name of plants used } & \multirow[t]{2}{*}{ Concentration $(\mathrm{mg} / \mathrm{mL})$} & \multicolumn{2}{|c|}{ Zone of inhibition (mm) } \\
\hline & & E. coli & MRSA \\
\hline & 15 & - & $5 \pm 0.9$ \\
\hline \multirow[t]{5}{*}{ Cucurbita sp. } & 20 & - & $7 \pm 1.2$ \\
\hline & 25 & - & $7 \pm 0.8$ \\
\hline & 30 & - & $8 \pm 1.2$ \\
\hline & 35 & - & $8 \pm 1.4$ \\
\hline & 15 & - & $10 \pm 1.2$ \\
\hline \multirow[t]{5}{*}{ M. indica } & 20 & $6 \pm 0.4$ & $10 \pm 0.8$ \\
\hline & 25 & $6 \pm 0.4$ & $11 \pm 0.9$ \\
\hline & 30 & $7 \pm 0.8$ & $11 \pm 0.5$ \\
\hline & 35 & $7 \pm 0.7$ & $13 \pm 0.9$ \\
\hline & 15 & - & - \\
\hline \multirow[t]{5}{*}{ A. heterophyllus Lam } & 20 & $6 \pm 0.5$ & $5 \pm 0.3$ \\
\hline & 25 & $6 \pm 0.3$ & $6 \pm 0.4$ \\
\hline & 30 & $7 \pm 0.1$ & $6 \pm 0.9$ \\
\hline & 35 & $7 \pm 0.5$ & $7 \pm 0.7$ \\
\hline & 15 & $6 \pm 0.7$ & $8 \pm 0.7$ \\
\hline \multirow[t]{5}{*}{ C. papaya $\mathrm{L}$. } & 20 & $7 \pm 0.7$ & $9 \pm 0.9$ \\
\hline & 25 & $7 \pm 0.6$ & $11 \pm 1.3$ \\
\hline & 30 & $8 \pm 0.6$ & $11 \pm 0.3$ \\
\hline & 35 & $9 \pm 0.3$ & $13 \pm 0.1$ \\
\hline & 15 & $7 \pm 0.1$ & $5 \pm 0.3$ \\
\hline \multirow[t]{5}{*}{ N. lappaceum } & 20 & $9 \pm 0.4$ & $7 \pm 0.5$ \\
\hline & 25 & $9 \pm 0.3$ & $8 \pm 0.3$ \\
\hline & 30 & $10 \pm 0.4$ & $9 \pm 0.4$ \\
\hline & 35 & $11 \pm 0.5$ & $11 \pm 0.9$ \\
\hline & 15 & $8 \pm 0.7$ & $7 \pm 0.6$ \\
\hline \multirow[t]{4}{*}{ D. zibethinus } & 20 & $8 \pm 0.7$ & $8 \pm 0.4$ \\
\hline & 25 & $9 \pm 0.4$ & $10 \pm 0.4$ \\
\hline & 30 & $9 \pm 0.3$ & $10 \pm 0.8$ \\
\hline & 35 & $12 \pm 0.1$ & $11 \pm 0.1$ \\
\hline Positive control & 10 & $28 \pm 1.1$ & $32 \pm 1.7$ \\
\hline Negative control & & - & - \\
\hline
\end{tabular}

Data represent mean \pm standard deviation; -: no zone of inhibition. 


\section{Conclusion}

Qualitative phytochemical analysis revealed that seed extracts are useful due to the existence of important phytochemical compounds such as glycosides, saponins, flavonoids, tannins, and alkaloids as they possess therapeutic effects that can be used for various treatments. This is further proven that it can be useful in the development in various novel chemotherapeutic agents or templates such as from plants which in the future, may lead to the production of synthetically improved therapeutic agents. Variations had been seen in the inhibition zone as it depends on the species and different seed extracts concentrations used for bacteria and it was observed that the highest inhibition zones were $M$. indica and $C$. papaya $\mathrm{L}$. The outcomes attained in this study have provided extensive information that allows the usage of seed extracts from agrowaste to be used in the management of microfobial infections. This indicated that it can be implemented as raw sources for food, chemical, and pharmaceutical industries.

\section{References}

[1] Khalaf, A. A., Desa, S., and Baharum, S. N. B. 2019. "Overview of Selected Native Seeds in Agricultural Wastes and its Properties." Medico-Legal Update 19 (2): 324-30.

[2] Sabiiti, E. N., Bareeba, F. B., Sporndly, E., Tenywa, J. S., Ledin, S., Ottabong, E., et al. 2004. "Urban Market Garbage: A Hidden Resource for Sustainable Urban/Peri-urban Agriculture and the Environment in Uganda." The Uganda Journal 50: 102-9.

[3] Da Silva, A. C., and Jorge, N. 2014. "Bioactive Compounds of the Lipid Fractions of Agro-industrial Waste." Food Research International 66: 493-500.

[4] Rinaldi, M. V. N., Díaz, I. E. C., Suffredini, I. B., and Moreno, P. R. H. 2017. Alkaloids and Biological Activity of Beribá (Annona hypoglauca)." Revista Brasileira de Farmacognosia 27 (1): 77-83.

[5] Jayakumar, S., Yusoff, M. M., Rahim, M. H. A., Maniam, G. P., and Govindan, N. 2017. "The Prospect of Microalgal Biodiesel Using Agro-industrial and Industrial Wastes in Malaysia.” Renewable and Sustainable Energy Reviews 72: 33-47.

[6] Agamuthu, P. 2009. "Challenges and Opportunities in
Agro-Waste Management: An Asian Perspective." Presented at Inaugural Meeting of First Regional $3 R$ Forum in Asia. Tokyo, Japan. http://www.malaxi.com.

[7] Babbar, N., Oberoi, H. S., Uppal, D. S., and Patil, R. T. 2011. "Total Phenolic Content and Antioxidant Capacity of Extracts Obtained from Six Important Fruit Residues." Food Research International 44 (1): 391-6.

[8] Dias, L. S., Luzia, D. M., and Jorge, N. 2013. "Physicochemical and Bioactive Properties of Hymenaea courbaril L. Pulp and Seed Lipid Fraction." Industrial Crops and Products 49: 610-8.

[9] Wu, S., Tokuda, M., Kashiwagi, A., Henmi, A., Okada, Y., Tachibana, S., and Nomura, M. 2015. "Evaluation of the Fatty Acid Composition of the Seeds of Mangifera indica L. and Their Application." Journal of Oleo Science 64 (5): 479-84.

[10] Maier, T., Schieber, A., Kammerer, D. R., and Carle, R. 2009. "Residues of Grape (Vitis vinifera L.) Seed Oil Production as a Valuable Source of Phenolic Antioxidants." Food Chemistry 112 (3): 551-9.

[11] Deyab, M., Elkatony, T., and Ward, F. 2016. "Qualitative and Quantitative Analysis of Phytochemical Studies on Brown Seaweed, Dictyota dichotoma." IJEDR 4 (2): 674-8.

[12] Roopashree, T. S., Dang, R., Rani, S. R. H., and Narendra, C. 2008. Antibacterial Activity of Antipsoriatic Herbs: Cassia tora, Momordica charantia and Calendula officinalis." International Journal of Applied Research in Natural Products 1 (3): 20-8.

[13] Valgus, C., Souza, S. M. D., Smânia, E. F., and Smânia Jr, A. 2007. "Screening Methods to Determine Antibacterial Activity of Natural Products." Brazilian Journal of Microbiology 38 (2): 369-80.

[14] Oduje, A. A., Awode, A., Edah, A., and Sagay, I. 2015. "Characterization and Phytochemical Screening of N-Hexane Oil Extract from Cissus aralioides Seeds." International Journal of Scientific and Engineering Research 6 (1): 112-6.

[15] Parthasarathy, V. A., and Zachariah, T. J. 2008. "10 Coriander." Chemistry of Spices, 190.

[16] Thirumurugan, K. 2010. "Antimicrobial Activity and Phytochemical Analysis of Selected Indian Folk Medicinal Plants." International Journal of Pharma Sciences and Research 1 (10): 430-4.

[17] Jayashree, D. 2013. "Phytochemicals Analysis and TLC Fingerprinting of Methanolic Extracts of Three Medicinal Plants." International Research Journal of Pharmacy 4 (6): 123-6.

[18] Ayoola, P. B., and Adeyeye, A. 2010. "Phytochemical and Nutrient Evaluation of Carica papaya (Pawpaw) Leaves." Ijrras 5 (3): 325-8. 
[19] Nayak, D. 2012. "Antibacterial, Antioxidant and Phytochemical Screening of Hibiscus rosa sinensis, Acorus calamus, Cucurbita maxiam and Moringa oliefera." MSc thesis, National Institute of Technology, Rourkela.

[20] Sulistiyaningsih, S., Mudin, N. S., Wicaksono, I. A., and Budiman, A. 2018. "Antibacterial Activity of Ethanol Extract and Fraction of Rambutan leaf (Nephelium lappaceum) against Pseudomonas aeruginosa Multiresistant." National Journal of Physiology, Pharmacy and Pharmacology 8 (2): 257-61.

[21] Basri, N. A., Ramli, A. T., and Aliyu, A. S. 2015. Malaysia Energy Strategy towards Sustainability: A Panoramic Overview of the Benefits and Challenges."
Renew Sustain Energy Rev 42: 1094-105.

[22] Aniel, K. O., Mutyala, N. L., and Rao, K, G. R., 2010. "In Vitro Antibacterial Activity in the Extracts of Andrographis paniculata Burm. F." International Journal of Pharm Tech Research 2 (2): 1383-5.

[23] Zaidan, M. R., Noor, R. A.,. Badrul, A. R., Adlin, A., Norazah, A., and Zakiah, I. 2005. "In Vitro Screening of Five Local Medicinal Plants for Antibacterial Activity Using Disc Diffusion Method." Tropical Biomedicine 22 (2): 165-70.

[24] Nikaido, H. 2003. "Molecular Basic of Bacterial Outer Membrane Permeability Revisited." Microbiology and Molecular Biology Reviews 67 (4): 593-656. 